\title{
Impact of magnetic resonance imaging and urodynamic studies on the management of sacrococcygeal dimples
}

\author{
Goichiro Tamura, MD, Nobuhito Morota, MD, and Satoshi Ihara, MD \\ Division of Neurosurgery, Tokyo Metropolitan Children's Medical Center, Tokyo, Japan
}

\begin{abstract}
OBJECTIVE Sacrococcygeal dimples in neonates and infants are of uncertain pathological import. Previously they were believed to be rarely associated with intraspinal anomalies. Recent studies using MRI, however, revealed that $6 \%-$ $7 \%$ of pediatric cases of sacrococcygeal dimples were associated with anatomical tethered spinal cord (TSC). Because the prevalence of tethered cord syndrome is still unclear, there is no consensus among pediatric neurosurgeons on the management of children with sacrococcygeal dimples. The authors performed an analysis of MRI and urodynamic studies to validate their management strategy for pediatric cases of sacrococcygeal dimples.
\end{abstract}

METHODS A total of 103 Japanese children (49 male and 54 female, median age 4 months, range 8 days-83 months) with sacrococcygeal dimples who were referred to the Division of Pediatric Neurosurgery between 2013 and 2015 were included in this study. The lumbosacral region of all the patients was investigated using MRI. Anatomical TSC was defined as a condition in which the caudal end of the conus medullaris is lower than the inferior border of the L2-3 intervertebral disc. Patients with minor spinal anomalies (e.g., anatomical TSC, filum lipoma, thickened filum, or filar cyst) underwent further urodynamic studies to ascertain the presence of neurogenic bladder (NGB). In this study, the presence of NGB without anatomical TSC but with other minor spinal anomalies was defined as "functional TSC." The prevalence of anatomical and functional TSC was investigated. The association of the following cutaneous findings with spinal anomalies was also assessed: 1) depth of the dimple, 2) deviation of the gluteal fold, and 3) other skin abnormalities (e.g., discoloration, angioma, or abnormal hair).

RESULTS The children were classified into 4 groups: Group 1, patients with anatomical TSC; Group 2, patients with functional TSC; Group 3, patients without anatomical or functional TSC but with other minor spinal anomalies; and Group 4, patients with no spinal anomaly. There were 6 patients (5.8\%) in Group 1, 8 patients (7.8\%) in Group 2, 10 patients $(9.7 \%)$ in Group 3, and 79 patients (76.7\%) in Group 4. Twenty-four patients (23.3\%; Groups 1, 2, and 3) showed MRI abnormalities, including filum lipoma (14 cases), filar cysts ( 5 cases), thickened filum ( 2 cases), and anatomical TSC without other spinal anomalies ( 3 cases). Untethering of the spinal cord was indicated for 14 patients (13.6\%; Groups 1 and 2) with anatomical and functional TSCs. Preoperative NGB was found in 12 patients and improved postoperatively in 7 (58.3\%). None of the associated lumbosacral skin findings predicted the presence of underlying spinal anomalies.

CONCLUSIONS The prevalence of tethered cord syndrome among children with sacrococcygeal dimples was, for the first time, revealed to be higher than previously thought. MRI and supplemental urodynamic studies may be indicated for children with sacrococcygeal dimples to identify patients with symptomatic TSC.

https://thejns.org/doi/abs/10.3171/2017.5.PEDS16719

KEY WORDS sacrococcygeal dimples; tethered spinal cord; urodynamic studies; neurogenic bladder; tethered cord syndrome; spine

$\mathrm{T}$ HE sacrococcygeal dimple is a soft-tissue depression or pit within the gluteal fold over the sacral or coccygeal region. Differing from other skin stigmata associated with underlying spinal anomalies, they are often called "low-risk skin stigmata." There is as yet no consensus among pediatric neurosurgeons regarding the management of such cases. Ponger et al. ${ }^{26}$ conducted an international survey of experienced neurosurgeons to ask how they examined the simple dimple, defined as a softtissue depression located up to $2.5 \mathrm{~cm}$ above the anus or within coccygeal proximity. The results of the survey revealed that $48 \%$ of pediatric neurosurgeons did not rec-

ABBREVIATIONS NGB = neurogenic bladder, OTCS = occult tethered cord syndrome; TSC = tethered spinal cord; VCUG = voiding cystourethrography . SUBMITTED December 27, 2016. ACCEPTED May 1, 2017.

INCLUDE WHEN CITING Published online July 7, 2017; DOI: 10.3171/2017.5.PEDS16719. 
ommend any type of imaging study, 30\% recommended ultrasound screening, and only $22 \%$ recommended MRI. ${ }^{26}$

Sacrococcygeal dimples reportedly occur in $2 \%-6 \%$ of healthy newborns..$^{10,21,27,35}$ The results of several previous studies, mostly using ultrasonography, suggested that sacrococcygeal dimples are rarely associated with a significant risk of spinal anomalies..$^{13,14,35}$ Ben-Sira et al. ${ }^{3}$ screened 109 neonates with simple dimples ultrasonographically and reported no pathological findings. However, the results of ultrasonographic screening were limited both by the skill of the technician and the amount of vertebral ossification. ${ }^{12}$ Chern et al. ${ }^{4}$ correlated lumbar ultrasonography with MRI findings in 103 patients with spinal dysraphism and reported poor sensitivity (76.9\%) for ultrasonography in detecting an abnormal conus position. Gomi et al. ${ }^{11}$ classified simple dimples into 2 subgroups: dimples located within the gluteal fold and those located at the upper edge of the gluteal fold. MRI showed no anatomical tethered spinal cord (TSC; defined by the location of the conus medullaris below the L2-3 intervertebral disc) in any of the 65 patients with the former type but showed an association with anatomical TSC in $3(6.4 \%)$ of the 47 patients with the latter type. Similarly, Harada et al. ${ }^{12}$ examined 84 cases of sacrococcygeal dimples occurring within the gluteal fold using MRI and found an association with anatomical TSC (with the conus level lower than the L-3 vertebral body) in 6 cases $(7.1 \%)$. The differences in these results could be attributed to different imaging modalities and criteria for TSC in each study, but the exact reasons are unclear. Currently, neurosurgical management for sacrococcygeal dimples in neonates and infants is confusing, and more data regarding the pathological import of this condition need to be gathered.26

The purpose of the present study was to validate our management strategy for pediatric cases of sacrococcygeal dimples. We examined the patients using MRI to ascertain the prevalence of anatomical TSC and other associated spinal anomalies. Our study was unique with respect to previously published reports in that we also performed urodynamic studies to ascertain the presence of neurogenic bladder (NGB) and identify candidates for surgery.

\section{Methods}

Between April 2013 and March 2015, a total of 154 consecutive native Japanese children with lumbosacral skin abnormalities were referred to the pediatric neurosurgery outpatient at Tokyo Metropolitan Children's Medical Center. The lumbosacral region of the spinal cord in these children was examined using a 1.5-T MRI scanner (Philips Electronics) under sedation. Only cases of sacrococcygeal dimples located within the gluteal fold (i.e., within $2.5 \mathrm{~cm}$ rostral to the anus or coccygeal proximity as previously defined $^{26}$ ) were included in this study. The location of the dimples within the gluteal fold (i.e., at the upper edge of the gluteal fold or within the coccygeal proximity as previously mentioned ${ }^{11}$ ) was not included for consideration because of the difficulty of describing it accurately, especially in neonates or small infants. Patients with major anorectal anomalies (e.g., unperforated anus, hypospadias, or persistent cloaca) were excluded, as were those with ma- jor spinal anomalies (e.g., conus lipoma or dermal sinus tract) and dimples located in the lumbar region. A total of 103 children with intragluteal dimples were included in this study. The study was approved by the institutional review board of our hospital.

In this study, anatomical TSC was diagnosed if the caudal end of the conus medullaris was located below the inferior border of the L2-3 intervertebral disc. The radiological diagnosis was made in a neuroradiology conference attended by at least 2 experienced pediatric neurosurgeons and 2 certified pediatric neuroradiologists. The midsagittal and axial views on balanced fast field echo (balanced FFE) MR images or similar high-resolution steady-state gradient echo sequences were used to determine the level of the conus medullaris.

Patients with anatomical TSC underwent urodynamic studies consisting of a voiding cystourethrography (VCUG) and cystometrogram. Patients without anatomical TSC but with other minor spinal anomalies such as filum lipoma, thickened filum (> $2 \mathrm{~mm}$ in diameter), or filar cysts also underwent urodynamic studies. Parameters evaluated by VCUG included total cystometric bladder capacity, shape or irregularity of the bladder wall, and postvoiding residual urine volume. Parameters examined by cystometrogram included intravesical pressure, abdominal pressure, and detrusor pressure during urine storage and voiding, as well as bladder compliance. The presence of detrusor overactivity or detrusor-sphincter dyssynergia was also assessed. For young children, a history of urinary tract infection, incontinence, and any urological symptoms were taken into consideration to determine the presence of NGB. For neonates and infants, urinary frequency and residual urine volume after voiding were also evaluated by applying an incontinence sensor and portable residual urine volume sensor. The final diagnosis of NGB was made in the urological conference attended by at least three certified pediatric urologists. If the patients had NGB and no anatomical TSC, their condition was designated as "functional TSC" in this study. Untethering of the spinal cord was indicated in patients with anatomical or functional TSC. These patients with NGB were followed for more than a year postoperatively and assessed with postoperative urodynamic studies.

The association of the following cutaneous findings with the prevalence of spinal anomalies was also assessed: 1) the depth of the dimples, 2) the deviation of the gluteal fold, and 3) other skin abnormalities (e.g., discoloration, angioma, or abnormal hair). As mentioned previously, a deep or shallow dimple was defined as a dimple in which the bottom was invisible or visible, respectively, when the skin was stretched. Deviation of the gluteal fold was defined as a lateral shift of $1 \mathrm{~cm}$ or more in the cleft from the midline or any skewed Y-shaped crease.

Statistical analysis was performed using the 2-tailed Fisher's exact test. A p value less than 0.05 was considered statistically significant.

\section{Results}

\section{Demographics and Classification}

The present study included 103 children (49 male and 


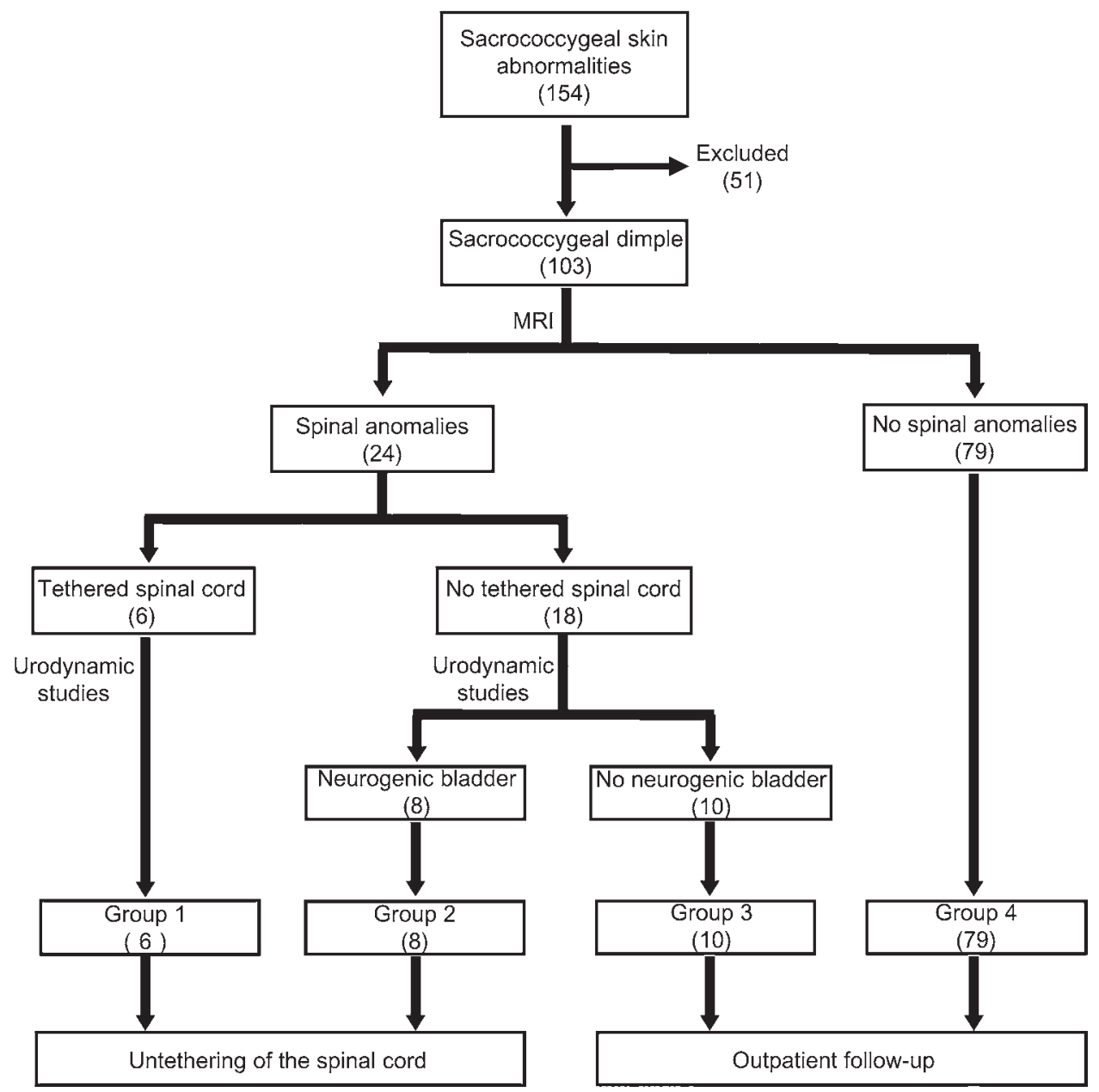

FIG. 1. Flowchart showing study design. Numerals in brackets indicate the number of cases.

54 female) with sacrococcygeal dimples located within the gluteal fold. The median age at their first visit was 4 months (mean 9.2 months, range 8 days -83 months). The median age at their first MRI was 6 months (mean 11.2 months, range 3-85 months). The children were classified into 4 groups based on the results of MRI and urodynamic studies (Fig. 1): Group 1, patients who had anatomical TSC (regardless of the presence of NGB); Group 2, patients who had functional TSC; Group 3, patients who had other minor spinal anomalies but no anatomical or functional TSC; and Group 4, patients who had no spinal anomaly. There were 6 patients (5.8\%) in Group 1, 8 patients (7.8\%) in Group 2, 10 patients $(9.7 \%)$ in Group 3, and 79 patients (76.7\%) in Group 4. Surgery was indicated for the patients in Groups 1 and 2. No surgical complication was observed in any patient. Patients in Groups 3 and 4 were closely observed in the urology and neurosurgery outpatient clinics. The results are summarized in Fig. 1 and Table 1.

\section{MRI Studies}

The median level of the conus medullaris in all the children with sacrococcygeal dimples was the superior half of L-2 (range L-1 to L3-4). The median level of the conus medullaris in all surgical cases was L2-3 (range L-1 to L3-4); in 6,2, and 6 patients the conus medullaris was located below L2-3, at L2-3, and above L2 -3 , respectively (Fig. 2). Group 1 included 2 patients with filum lipoma, 1 patient with a filar cyst, and 3 patients with only anatomical TSC. Filum lipoma was found in all 8 patients in Group 2. Group 3 included 4 patients with filum lipoma, 2 with thickened filum, and 4 with filar cyst. These results are summarized in Table 1. Overall, 24 patients (23.3\%) had MRI abnormalities, including filum lipoma (14 cases), filar cysts (5 cases), thickened filum (2 cases), and anatomical TSC without other spinal anomalies ( 3 cases). Detailed information on the patients in Groups 1,2, and 3 is shown in Table 2.

\section{Urodynamic Studies and Surgical Outcome}

Urodynamic studies of the 24 patients with spinal anomalies detected NGB in 12 patients (50.0\%), including 4 patients in Group 1 and all 8 patients in Group 2. Two patients in Group 1 had normal preoperative urodynamic results. Among the remaining 4 patients in Group $1,3(75.0 \%)$ showed an improvement in postoperative urodynamics, as did 4 patients (50.0\%) in Group 2. Overall, 7 (58.3\%) of 12 patients with preoperative NGB showed 
TABLE 1. Summary of the entire cohort

\begin{tabular}{|c|c|c|c|c|}
\hline Characteristic & Group 1 & Group 2 & Group 3 & Group 4 \\
\hline No. of cases & 6 & 8 & 10 & 79 \\
\hline \multicolumn{5}{|l|}{ Age in $\mathrm{mos}^{*}$} \\
\hline Median & 8.5 & 2 & 4.5 & 4 \\
\hline Range & $0-32$ & $1-25$ & $1-43$ & $0-83$ \\
\hline \multicolumn{5}{|l|}{ Sex (no. of cases) } \\
\hline Male & 2 & 1 & 5 & 41 \\
\hline Female & 4 & 7 & 5 & 38 \\
\hline \multicolumn{5}{|c|}{ Level of conus medullaris } \\
\hline Median & L-3 inf to L3-4 & L-2 inf & L-2 sup & L-2 sup \\
\hline Range & L-3 sup to L3-4 & $L-1$ inf to $L 2-3$ & $\mathrm{~L} 1-2$ to $\mathrm{L} 2-3$ & L-1 sup to $L 2-3$ \\
\hline \multicolumn{5}{|c|}{ Spinal anomalies (no. of cases) } \\
\hline Anatomical TSC & 6 & 0 & 0 & 0 \\
\hline Filum lipoma & 2 & 8 & 4 & 0 \\
\hline Filar cyst & 1 & 0 & 4 & 0 \\
\hline Thickened filum & 0 & 0 & 2 & 0 \\
\hline NGB (no. of cases) & 4 & 8 & 0 & NA \\
\hline
\end{tabular}

Inf $=$ inferior half of the vertebra; $N A=$ not available; sup = superior half of the vertebra.

${ }^{*}$ Age at time of first outpatient visit.

an improvement in their urodynamic studies 6 months to 1 year postoperatively. The results are shown in Table 2.

\section{Prevalence of NGB in Patients With and Without Anatomical TSC}

Four $(66.7 \%)$ of the 6 patients in Group 1 and 8 (44.5\%) of 18 patients in Groups 2 and 3 showed signs of NGB. Fisher's exact test revealed that patients with minor spinal anomalies but no anatomical TSC were not necessarily at lower risk of NGB compared with patients with

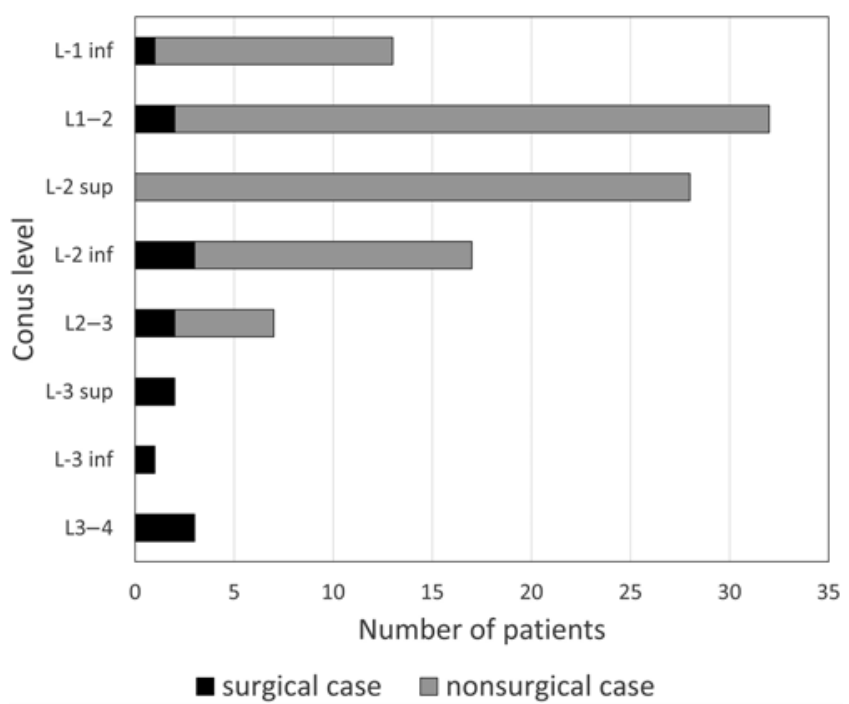

FIG. 2. The level of the conus medullaris and the number of patients in the cohort. Surgical and nonsurgical cases are shown by black and gray, respectively. inf = inferior half of the vertebra; sup = superior half of the vertebra. anatomical TSC $(\mathrm{p}=0.64)$. The results are summarized in Table 3.

\section{Associated Findings of the Skin and Spinal Anomalies}

The prevalence of spinal anomalies with and without each of the associated lumbosacral cutaneous findings was analyzed. Eleven patients had deep dimples, and 4 (36.4\%) of these 11 also had spinal anomalies. There were $92 \mathrm{pa}-$ tients with shallow dimples, and 20 (21.7\%) of these 92 had spinal anomalies. No significant difference was found between the two groups $(p=0.28)$. Similarly, the presence of gluteal fold deviation or other skin abnormalities (e.g., discoloration, hemangioma, or abnormal hair) did not increase the risk of associated minor spinal anomalies $(\mathrm{p}=$ 0.74 and 0.064 , respectively). The results are summarized in Table 4.

\section{A Representative Case}

A 1.5-year-old boy was referred to the Division of Pediatric Neurosurgery for examination of a shallow sacrococcygeal dimple located at the midline within the gluteal fold. No skin discoloration or abnormal hair was present. MRI revealed a filum lipoma and the conus medullaris at L-2 (Fig. 3A-C). Preoperative VCUG revealed an increased total cystometric bladder capacity, no irregular thickening of the bladder wall, and a moderate amount of residual urine volume $(35 \mathrm{ml})$. Preoperative cystometrogram revealed continuously increased detrusor pressure during urine storage and low bladder compliance $\left(78 \mathrm{ml} / 20 \mathrm{~cm} \mathrm{H} \mathrm{H}_{2} \mathrm{O}\right.$ $=3.9$ ) with no detrusor overactivity or detrusor-sphincter dyssynergia. The VCUG and cystometrogram findings were compatible with NGB. Untethering of the spinal cord by sectioning the filum lipoma was performed without any complication. Postoperative MRI confirmed the success- 
TABLE 2. Detailed summary of the 24 cases in Groups 1,2 , and 3

\begin{tabular}{|c|c|c|c|c|c|}
\hline Group \& Case No. & Age (mos), Sex* & Level of Conus Medullaris & Other Spinal Anomalies & Preop NGB & Postop Urodynamics \\
\hline \multicolumn{6}{|l|}{ Group 1} \\
\hline 1 & $9, \mathrm{~F}$ & L-3 sup & None & + & Improved \\
\hline 2 & $32, \mathrm{M}$ & L-3 sup & None & + & Improved \\
\hline 3 & $4, \mathrm{~F}$ & $L-3$ inf & None & - & NA \\
\hline 4 & $0, \mathrm{~F}$ & L3-4 & Filum lipoma & + & Improved \\
\hline 5 & $8, M$ & L3-4 & Filum lipoma & - & Unchanged \\
\hline 6 & $19, \mathrm{~F}$ & L3-4 & Filar cyst & + & Unchanged \\
\hline \multicolumn{6}{|l|}{ Group 2} \\
\hline 7 & $1, M$ & $L-1$ inf & Filum lipoma & + & Improved \\
\hline 8 & $1, \mathrm{~F}$ & L1-2 & Filum lipoma & + & Improved \\
\hline 9 & $6, F$ & L1-2 & Filum lipoma & + & Unchanged \\
\hline 10 & $1, \mathrm{~F}$ & $L-2$ inf & Filum lipoma & + & Unchanged \\
\hline 11 & $15, F$ & $L-2$ inf & Filum lipoma & + & Improved \\
\hline 12 & $25, F$ & $L-2$ inf & Filum lipoma & + & Unchanged \\
\hline 13 & $1, \mathrm{~F}$ & L2-3 & Filum lipoma & + & Unchanged \\
\hline 14 & $3, F$ & L2-3 & Filum lipoma & + & Improved \\
\hline \multicolumn{6}{|l|}{ Group 3} \\
\hline 15 & $1, F$ & L1-2 & Filum lipoma & - & NA \\
\hline 16 & $1, \mathrm{~F}$ & L1-2 & Filar cyst & - & NA \\
\hline 17 & $19, \mathrm{M}$ & L1-2 & Filum lipoma & - & NA \\
\hline 18 & $25, M$ & L1-2 & Filum lipoma & - & NA \\
\hline 19 & $4, M$ & L-2 sup & Filum lipoma & - & NA \\
\hline 20 & $4, F$ & L-2 sup & Filar cyst & - & NA \\
\hline 21 & $10, F$ & L-2 sup & Thickened filum & - & NA \\
\hline 22 & $4, F$ & $L-2$ inf & Filar cyst & - & NA \\
\hline 23 & $5, M$ & $L-2$ inf & Filar cyst & - & NA \\
\hline 24 & $43, M$ & L2-3 & Thickened filum & - & NA \\
\hline
\end{tabular}

* Age at time of first outpatient visit.

ful sectioning of the filum lipoma (Fig. 2D). Postoperative VCUG showed the disappearance of the residual urine. A photograph of the sacrococcygeal dimple is shown in Fig. 2E. The preoperative cystometrogram is shown in Fig. $2 \mathrm{~F}$.

\section{Discussion}

\section{Group 1: Anatomical TSC}

Anatomical TSC is characterized by a pathological fixation of the spinal cord resulting in an abnormally low conus medullaris. This condition eventually results in ischemic damage of the normal neural tissue of the spinal

TABLE 3. Number of cases of NGB according to the presence of anatomical TSC

\begin{tabular}{lcc}
\hline & \multicolumn{2}{c}{ NGB } \\
\cline { 2 - 3 } Group & Present & Absent \\
\hline Group 1 (anatomical TSC) & 4 & 2 \\
\hline Groups 2 \& 3 (no anatomical TSC) & 8 & 10 \\
\hline
\end{tabular}

The prevalence of NGB in Group 1 and Groups 2 and 3 (combined) was not significantly different ( $p=0.64$, Fisher's exact test). cord, especially the interneuronal axonal connections requiring aerobic metabolism. ${ }^{1}$ Symptoms caused by anatomical TSC include neurological, musculoskeletal, and urological abnormalities. There is general agreement that

TABLE 4. Number of cases of spinal anomalies with and without each associated finding

\begin{tabular}{lrcc}
\hline \multirow{2}{*}{ Finding } & \multicolumn{2}{c}{ Spinal Anomalies } & \\
\cline { 2 - 3 } & Present & Absent & p Value* \\
\hline Depth & & & 0.28 \\
\hline Deep & 4 & 7 & \\
\hline Shallow & 20 & 72 & \\
\hline Gluteal fold deviation & & & 0.74 \\
\hline Present & 4 & 11 & \\
\hline Absent & 20 & 68 & \\
\hline Other skin abnormalitiest & & & 0.064 \\
\hline Present & 0 & 12 & \\
\hline Absent & 24 & 67 & \\
\hline
\end{tabular}

* The $p$ values were calculated using Fisher's exact test.

† Other skin abnormalities included discoloration, hemangioma, and abnormal hair present in the lumbosacral region. 

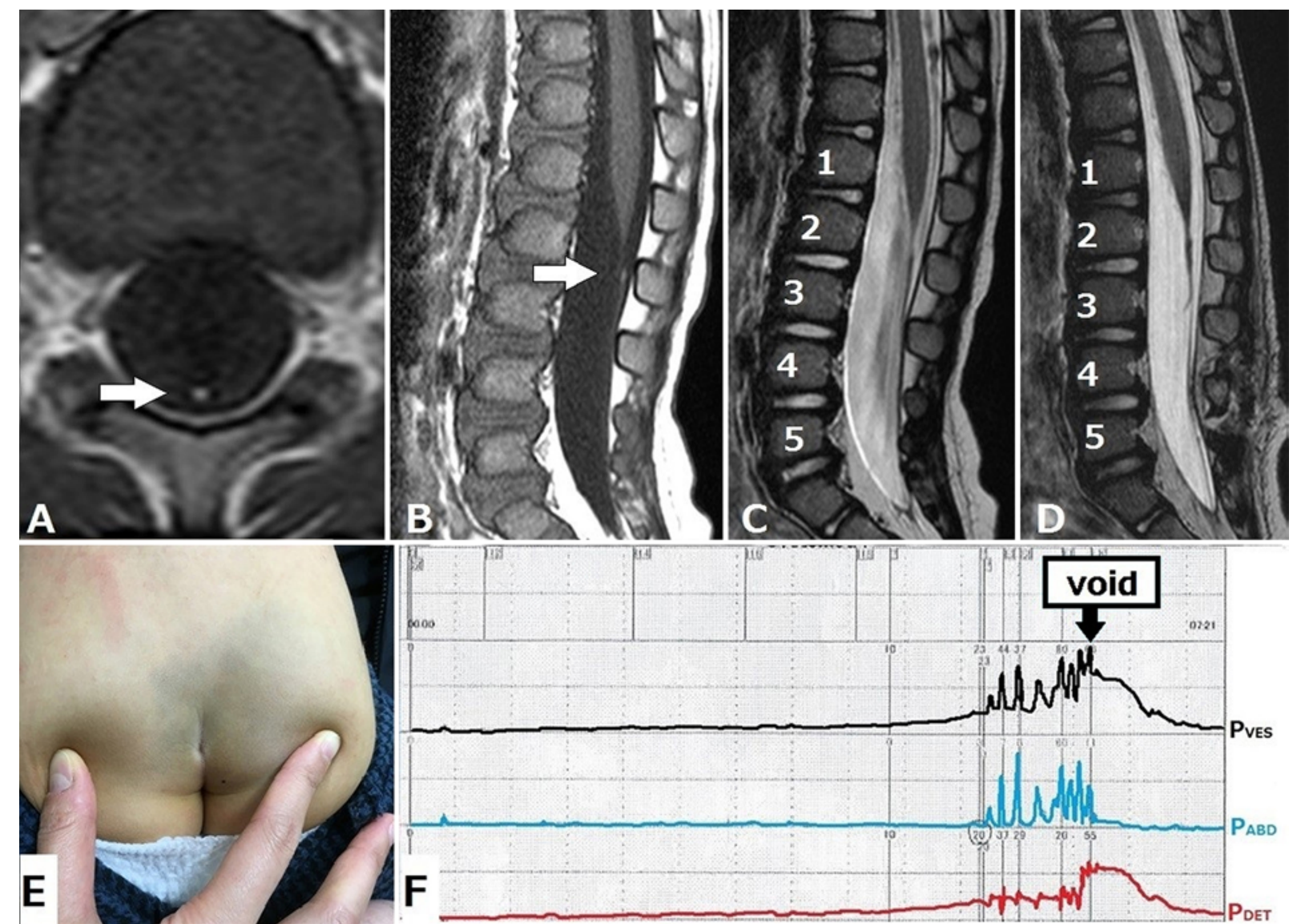

FIG. 3. Representative case involving a 1.5-year-old boy with a sacrococcygeal dimple. A-C: Preoperative axial (A) and sagittal (B) T1-weighted MR images showing the filum lipoma (arrows) and sagittal T2-weighted MR image showing the normal level of conus medullaris (L-2). The numerals indicate the level of the lumbar vertebrae. D: Postoperative sagittal T2-weighted MR image showing the sectioned filum lipoma. E: Photograph of the shallow sacrococcygeal dimple within the gluteal fold. F: Preoperative cystometrogram showing intravesical pressure $\left(P_{\mathrm{VES}}\right)$, abdominal pressure $\left(\mathrm{P}_{\mathrm{ABD}}\right)$, and detrusor pressure $\left(\mathrm{P}_{\mathrm{DET}}=\mathrm{P}_{\mathrm{VES}}-\mathrm{P}_{\mathrm{ABD}}\right)$ during storage and voiding phases. The start of voiding is indicated by "void." The bladder compliance is low $\left(78 \mathrm{ml} / 20 \mathrm{~cm} \mathrm{H}_{2} \mathrm{O}=3.9\right)$. The results are compatible with NGB. Figure is available in color online only.

symptomatic patients with anatomical TSC require surgical intervention. ${ }^{6,8}$ Because urological deficits may still not have fully developed early in life, early untethering prevents the deterioration of bladder function that can lead to NGB as well as preventing the development of orthopedic deformities. As a rule, the earlier the operation, the better the long-term outcome., ${ }^{9,17,32,37}$

It is important to diagnose anatomical TSC accurately during the early stages of life. The exact level of the conus medullaris at the time of birth is controversial, but the conus medullaris is normally located above the middle of L-2 by 3 months of age. ${ }^{2,36}$ Barkovich $^{2}$ stated that in several series involving more than 1000 patients, the caudal end of the conus was observed above the L2-3 level in more than $98 \%$ of cases and at the L-3 level in less than $2 \%$. It is noteworthy, however, that the anatomical definition of low conus varies among researchers. Barkovich proposed that a conus medullaris terminating below the inferior endplate of L-2 should be considered abnormal. Others defined low conus as located below the inferior border of the L2 -3 intervertebral disc space..$^{11}$ In this study we defined anatomical TSC as a condition in which the caudal end of the conus medullaris is located below the inferior border of the L2-3 intervertebral disc. It is also worth noting that the diagnosis of anatomical TSC should be made after patients are 3 months old. Although ultrasonography is widely used to screen for spinal anomalies, it is less accurate when examining infants older than 3-6 months because the posterior lamina begins to ossify around this time..$^{11,12}$ Therefore, all patients in this study were examined by MRI when they were 3 months old or older.

Our data revealed that $6(5.8 \%)$ of the 103 children with sacrococcygeal dimples had anatomical TSC. This result approximates that of previous MRI studies reporting the association of anatomical TSC with sacrococcygeal dimples in $6 \%-7 \%$ of the children examined. ${ }^{11,12}$ Our data also revealed that untethering improved the urodynamic results in $3(75 \%)$ of the 4 patients with preoperative NGB in Group 1. The remaining 2 patients with normal preoperative urodynamic results also underwent prophylactic untethering. One of these, a patient with filum lipoma (Case 5, Table 2), showed normal postoperative urodynamic study results, and the other (Case 3) showed no clinical symptoms postoperatively during the follow-up period. 


\section{Group 2: Functional TSC}

There is a consensus that the spinal cord should be untethered in symptomatic patients. However, detecting the earliest signs of urological or neurological deterioration before symptoms become irreversible is difficult. Urological symptoms were reportedly either absent or rare in patients younger than 1.5 years, whereas urodynamic studies were effective in detecting subclinical bladder dysfunction in about $40 \%-60 \%$ of cases. ${ }^{9,17}$ In the present study, patients with urodynamic abnormalities were considered to be "symptomatic" even though they presented no clinical symptoms such as incontinence, urinary retention, or urinary tract infection. Urodynamic studies are especially useful for providing objective data for surgical indication in neonates and young infants who have an otherwise normal clinical history ${ }^{16,19,24}$ For patients with filum lipoma or thickened filum, previous reports stressed the importance of performing urodynamic studies to screen for possible $\mathrm{NGB}$, and in the event that abnormalities were found, to perform untethering. ${ }^{22,25}$

This study found that $8(7.8 \%)$ of 103 children with sacrococcygeal dimples were associated with functional TSC (Group 2). The conus position of the cases in Group 2 ranged from the inferior half of L-1 to L2-3 (with the median level being the inferior half of L-2). Moreover, the prevalence of NGB in patients with a normally positioned conus and minor spinal anomalies (Groups 2 and 3) was about the same as for patients with a low conus (Group 1), as shown in Table $3(\mathrm{p}=0.64)$. We therefore recommend performing urodynamic studies to identify candidates for surgery regardless of the level of the conus if MRI reveals the presence of minor spinal anomalies.

Tethered cord syndrome can be present with the conus in a normal position, a condition called occult tethered cord syndrome (OTCS). In the present study, we used the term "functional TSC" instead of OTCS for Group 2 due to the controversial nature of the concept of OTCS. In the 1990s, patients presenting with urological symptoms suggestive of tethered cord syndrome but with a normally positioned conus were first reported by several researchers. ${ }^{18,34}$ This condition was later described as OTCS. Subsequent studies confirmed that the conus was in the normal position in about $14 \%$ to $28 \%$ of patients with tethered cord syndrome. . $^{15,30,31,34}$ Its most common presentation was NGB, observed in $68 \%-100 \%$ of the patients. . $^{72,23,28,30}$ However, the radiological inclusion criteria differed slightly among these studies. In the earliest studies done in the $1990 \mathrm{~s}, 18,34$ the patients did not show any obvious, associated intraspinal anomaly or occult spinal bony dysraphism. However, when Steinbok et al. ${ }^{29}$ reported their first randomized controlled study of OTCS in 2016, they included patients with a filum of any size and with any amount of fat. These differences give rise to the question of whether the cases in all of these studies can be treated equally as cases of OTCS. Thus because OTCS is a recently defined entity and the concept remains controversial, ${ }^{30}$ we avoided the term "occult" when describing the cases in Group 2.

\section{Group 3: Asymptomatic Patients With Minor Spinal Anomalies and Normally Positioned Conus}

Prophylactic untethering for asymptomatic patients with no anatomical TSC is still controversial. Some cli- nicians favor prophylactic surgery because sectioning the filum terminale or simple filum lipoma is a relatively safe procedure with a very low complication rate compared to the untethering of larger conus lipomas. ${ }^{18,22,33}$ However, the natural history of minor spinal anomalies (e.g., filum lipoma, thickened filum, or filar cyst) is not well understood. ${ }^{5}$ We therefore believe it is prudent to perform untethering of the normally positioned spinal cord only for the patients with both minor spinal anomalies and urodynamic abnormalities (i.e., Group 2), and to observe those with no urodynamic abnormalities closely (i.e., Group 3). No one in Group 3 showed clinical signs of tethered cord syndrome during the follow-up period.

\section{Skin Abnormalities and Prevalence of Spinal Anomalies}

Our MRI data showed that 24 (23.3\%; Groups 1, 2, and $3)$ of 103 children with sacrococcygeal dimples were associated with minor spinal anomalies. None of the associated cutaneous findings in the lumbosacral region in this study predicted underlying spinal anomalies (Table 4). Harada et al. ${ }^{12}$ previously reported that deep dimples were more likely to be associated with intraspinal anomalies (e.g., filum lipoma). However, the prevalence of spinal anomalies in the present study did not differ significantly between patients with deep and shallow dimples $(\mathrm{p}=0.28)$, partly because the depth of the dimples was sometimes difficult to determine due to the dramatic increase in subcutaneous fatty tissue, especially during the first few months after birth. ${ }^{11}$ Further, the presence of a deviated gluteal fold was not associated with an increased risk of spinal anomalies $(p=0.74)$. The presence of skin abnormalities other than dimples (e.g., skin discoloration, hemangioma, or abnormal hair) was only weakly associated with the absence of spinal anomalies and failed to show statistical significance in a 2-tailed Fisher's exact test $(\mathrm{p}=0.064)$. Although the precise reasons for this are unclear, sample bias may have played a role, as shown in Table 4; none of the 12 patients with other skin abnormalities had spinal anomalies. In our study the presence of associated cutaneous findings did not correlate with an increase in the risk of spinal anomalies in children with sacrococcygeal dimples, thus illustrating the difficulty of determining which patients with sacrococcygeal dimples should be subjected to further radiological examination. It is our policy, therefore, to recommend MRI for all children with sacrococcygeal dimples.

\section{Group 4: Patients With No Spinal Anomalies}

Children with no MRI abnormalities underwent outpatient observation. No one in this group showed any clinical symptoms during the follow-up period. This group of patients constituted the majority (79 [76.7\%] of 103) of the children with intragluteal sacrococcygeal dimples.

\section{Limitations}

A limitation of the present study lies in the fact that the patients in Group 4 did not undergo urodynamic studies. There was no prospective study investigating the prevalence of NGB among children with only sacrococcygeal dimples. Because of the invasive nature of urodynamic studies, it was not feasible to perform them in asymptom- 
atic patients with no MRI abnormalities (i.e., Group 4) in the present study. Future prospective studies are needed to ascertain the overall prevalence of NGB among children with sacrococcygeal dimples. Our results were nevertheless of clinical importance because the prevalence of tethered cord syndrome among children with sacrococcygeal dimples was shown to be higher than previously expected.

\section{Conclusions}

Our study found the prevalence of anatomical TSC among children with sacrococcygeal dimples to be $5.8 \%$ (6 of 103 cases) and that of functional TSC to be 7.8\% (8 of 103 cases). Untethering of the spinal cord, indicated in 14 cases (14.4\%), was performed with no surgical complication, and postoperative urological function improved in $58.3 \%$ of patients. Our data revealed that the prevalence of tethered cord syndrome among children with sacrococcygeal dimples was higher than previously expected, but that predicting it based on the associated cutaneous findings without MRI or urodynamic studies was difficult. We recommend that children with sacrococcygeal dimples may benefit from spinal MRI and, if any spinal anomaly is found, that urodynamic studies be conducted for further examination.

\section{Acknowledgments}

We thank Drs. Gen Nishimura and Kazutoshi Fujita of the Department of Radiology, Tokyo Metropolitan Children's Medical Center, for evaluating the MRI, and Drs. Hiroyuki Sato, Zenichi Matsui, and Yujiro Aoki of the Department of Urology, Tokyo Metropolitan Children's Medical Center, for conducting the urological assessment. We also thank Mr. James Robert Valera for his editorial assistance.

\section{References}

1. Alsowayan O, Alzahrani A, Farmer JP, Capolicchio JP, Jednak R, El-Sherbiny M: Comprehensive analysis of the clinical and urodynamic outcomes of primary tethered spinal cord before and after spinal cord untethering. J Pediatr Urol 12:285.e1-285.e5, 2016

2. Barkovich AJ: Normal conus medullaris and filum terminale, in Barkovich AJ, Raybaud C (eds): Pediatric Neuroimaging, ed 5. Philadelphia: Lippincott Williams \& Wilkins, 2012, p 883

3. Ben-Sira L, Ponger P, Miller E, Beni-Adani L, Constantini S: Low-risk lumbar skin stigmata in infants: the role of ultrasound screening. J Pediatr 155:864-869, 2009

4. Chern JJ, Aksut B, Kirkman JL, Shoja MM, Tubbs RS, Royal SA, et al: The accuracy of abnormal lumbar sonography findings in detecting occult spinal dysraphism: a comparison with magnetic resonance imaging. J Neurosurg Pediatr 10:150-153, 2012

5. Cools MJ, Al-Holou WN, Stetler WR Jr, Wilson TJ, Muraszko KM, Ibrahim M, et al: Filum terminale lipomas: imaging prevalence, natural history, and conus position. J Neurosurg Pediatr 13:559-567, 2014

6. Drake JM: Surgical management of the tethered spinal cord-walking the fine line. Neurosurg Focus 23(2):E4, 2007

7. Fabiano AJ, Khan MF, Rozzelle CJ, Li V: Preoperative predictors for improvement after surgical untethering in occult tight filum terminale syndrome. Pediatr Neurosurg 45:256261, 2009
8. Finn MA, Walker ML: Spinal lipomas: clinical spectrum, embryology, and treatment. Neurosurg Focus 23(2):E10, 2007

9. Foster LS, Kogan BA, Cogen PH, Edwards MS: Bladder function in patients with lipomyelomeningocele. J Urol 143:984-986, 1990

10. Gibson PJ, Britton J, Hall DM, Hill CR: Lumbosacral skin markers and identification of occult spinal dysraphism in neonates. Acta Paediatr 84:208-209, 1995

11. Gomi A, Oguma H, Furukawa R: Sacrococcygeal dimple: new classification and relationship with spinal lesions. Childs Nerv Syst 29:1641-1645, 2013

12. Harada A, Nishiyama K, Yoshimura J, Sano M, Fujii Y: Intraspinal lesions associated with sacrococcygeal dimples. J Neurosurg Pediatr 14:81-86, 2014

13. Haworth JC, Zachary RB: Congenital dermal sinuses in children; their relation to pilonidal sinuses. Lancet 269:10-14, 1955

14. Henriques JG, Pianetti G, Henriques KS, Costa P, Gusmão S: Minor skin lesions as markers of occult spinal dysraphismsprospective study. Surg Neurol 63 (Suppl 1):S8-S12, 2005

15. Hendrick EB, Hoffman HJ, Humphreys RP: The tethered spinal cord. Clin Neurosurg 30:457-463, 1983

16. Hsieh MH, Perry V, Gupta N, Pearson C, Nguyen HT: The effects of detethering on the urodynamics profile in children with a tethered cord. J Neurosurg 105 (5 Suppl):391-395, 2006

17. Keating MA, Rink RC, Bauer SB, Krarup C, Dyro FM, Winston KR, et al: Neurourological implications of the changing approach in management of occult spinal lesions. J Urol 140:1299-1301, 1988

18. Khoury AE, Hendrick EB, McLorie GA, Kulkarni A, Churchill BM: Occult spinal dysraphism: clinical and urodynamic outcome after division of the filum terminale. J Urol 144:426-429, 443-444, 1990

19. Kim SW, Ha JY, Lee YS, Lee HY, Im YJ, Han SW: Sixmonth postoperative urodynamic score: a potential predictor of long-term bladder function after detethering surgery in patients with tethered cord syndrome. J Urol 192:221-227, 2014

20. Komagata M, Endo K, Nishiyama M, Ikegami H, Imakiire A: Management of tight filum terminale. Minim Invasive Neurosurg 47:49-53, 2004

21. Kriss VM, Desai NS: Occult spinal dysraphism in neonates: assessment of high-risk cutaneous stigmata on sonography. AJR Am J Roentgenol 171:1687-1692, 1998

22. La Marca F, Grant JA, Tomita T, McLone DG: Spinal lipomas in children: outcome of 270 procedures. Pediatr Neurosurg 26:8-16, 1997

23. Metcalfe PD, Luerssen TG, King SJ, Kaefer M, Meldrum KK, Cain MP, et al: Treatment of the occult tethered spinal cord for neuropathic bladder: results of sectioning the filum terminale. J Urol 176:1826-1830, 2006

24. Meyrat BJ, Tercier S, Lutz N, Rilliet B, Forcada-Guex M, Vernet $\mathrm{O}$ : Introduction of a urodynamic score to detect preand postoperative neurological deficits in children with a primary tethered cord. Childs Nerv Syst 19:716-721, 2003

25. Pierre-Kahn A, Zerah M, Renier D, Cinalli G, Sainte-Rose C, Lellouch-Tubiana A, et al: Congenital lumbosacral lipomas. Childs Nerv Syst 13:298-335, 1997

26. Ponger P, Ben-Sira L, Beni-Adani L, Steinbok P, Constantini $\mathrm{S}$ : International survey on the management of skin stigmata and suspected tethered cord. Childs Nerv Syst 26:17191725,2010

27. Sasani M, Asghari B, Asghari Y, Afsharian R, Ozer AF: Correlation of cutaneous lesions with clinical radiological and urodynamic findings in the prognosis of underlying spinal dysraphism disorders. Pediatr Neurosurg 44:360-370, 2008

28. Steinbok P, Kariyattil R, MacNeily AE: Comparison of sec- 
tion of filum terminale and non-neurosurgical management for urinary incontinence in patients with normal conus position and possible occult tethered cord syndrome. Neurosurgery 61:550-556, 2007

29. Steinbok P, MacNeily AE, Hengel AR, Afshar K, Landgraf $\mathrm{JM}$, Hader W, et al: Filum section for urinary incontinence in children with occult tethered cord syndrome: a randomized, controlled pilot study. J Urol 195:1183-1188, 2016

30. Tu A, Steinbok P: Occult tethered cord syndrome: a review. Childs Nerv Syst 29:1635-1640, 2013

31. Tubbs RS, Oakes WJ: Can the conus medullaris in normal position be tethered? Neurol Res 26:727-731, 2004

32. Vernet O, Farmer JP, Houle AM, Montes JL: Impact of urodynamic studies on the surgical management of spinal cord tethering. J Neurosurg 85:555-559, 1996

33. Warder DE: Tethered cord syndrome and occult spinal dysraphism. Neurosurg Focus 10(1):e1, 2001

34. Warder DE, Oakes WJ: Tethered cord syndrome and the conus in a normal position. Neurosurgery 33:374-378, 1993

35. Weprin BE, Oakes WJ: Coccygeal pits. Pediatrics 105:E69, 2000

36. Wilson DA, Prince JR: John Caffey award. MR imaging determination of the location of the normal conus medullaris throughout childhood. AJR Am J Roentgenol 152:10291032,1989

37. White JT, Samples DC, Prieto JC, Tarasiewicz I: Systematic review of urologic outcomes from tethered cord release in occult spinal dysraphism in children. Curr Urol Rep 16:78, 2015

\section{Disclosures}

The authors report no conflict of interest concerning the materials or methods used in this study or the findings specified in this paper.

\section{Author Contributions}

Conception and design: all authors. Acquisition of data: all authors. Analysis and interpretation of data: Tamura, Morota. Drafting the article: Tamura. Critically revising the article:

Tamura, Morota. Reviewed submitted version of manuscript: all authors. Approved the final version of the manuscript on behalf of all authors: Tamura. Statistical analysis: Tamura. Study supervision: Morota.

\section{Correspondence}

Goichiro Tamura, Division of Neurosurgery, Tokyo Metropolitan Children's Medical Center, 2-8-29 Musashidai, Fuchu, Tokyo 1838561, Japan. email: g-tamura@umin.ac.jp. 